\title{
Uncommon Complications after Anterior Cruciate Ligament Reconstruction
}

\author{
Anna Palazzolo ${ }^{1}$ Federica Rosso ${ }^{2}$ Davide Edoardo Bonasia ${ }^{2}$ Francesco Saccia ${ }^{3}$ Roberto Rossi ${ }^{2}$ Knee \\ Committee SIGASCOT
}

${ }^{1}$ Department of Orthopedics and Traumatology, Università degli studi di Torino, Turin, Italy

${ }^{2}$ Department of Orthopaedics and Traumatology, AO Ordine Mauriziano, Turin, Italy

3 Orthopaedics and Traumatology Unit, San Giovanni Bosco Hospital, Turin, Italy

Joints 2018;6:188-203.
Address for correspondence Federica Rosso, MD, Department of Orthopaedics and Traumatology, AO Ordine Mauriziano, Largo Turati 62, 10128, Turin, Italy (e-mail: federica.rosso@yahoo.it).

\begin{abstract}
Keywords

- complication

- rare

- uncommon

- anterior cruciate ligament

- reconstruction

Anterior cruciate ligament reconstruction (ACL-R) is a common surgical procedure, with good outcome in 75 to $97 \%$ of the cases. However, different complications have been described including infection, hemarthrosis, deep vein thrombosis (DVT), and pulmonary embolism (PE) with a rate ranging from 1 to $15 \%$. There are few case reports in the literature describing rare complications after ACL-R and they can be divided into: (1) complications related to the fixation device (rupture, migration); (2) fractures (tibial or femoral side); (3) infections due to uncommon bacteria, mycobacterium, and mycosis; (4) rare vascular injuries; (5) nerve injuries; and (6) other rare complications. In case of fixation device rupture or migration, device removal can be easy but the diagnosis may be challenging. Patellar fracture after ACL-R may be related to harvesting and it is not uncommon. Conversely, femoral or tibial fractures are most frequently due to bone weakness related to bone tunnels. Some rare infections related to uncommon bacteria or mycosis are also described with potentially devastating joint damage. Popliteal artery injuries are uncommon in ACL-R but minor vessels damages are described with possible severe consequences for patients. Injuries to the infrapatellar branch of the saphenous nerve are not uncommon in ACL-R. However, there are few case reports also describing injuries to the saphenous nerve, the common peroneal nerve and the sciatic nerve. The aim of this paper is to review the literature describing uncommon complications after ACL-R, giving some more information about diagnosis and treatment.
\end{abstract}

\section{Introduction}

Anterior cruciate ligament reconstruction (ACL-R) is a very common surgical procedure, with more than 120,000 surgeries performed annually in the United States. ${ }^{1}$ Different studies reported good outcomes after ACL-R with a return to preinjury level of activity ranging from 75 to $97 \%{ }^{2-4}$ However, a failure rate ranging from 10 to $15 \%$ and a complication rate ranging from 1 to $15 \%$ are also reported. ${ }^{5,6}$ Complications after ACL-R, such as deep vein thrombosis (DVT), hemarthrosis, effusion and synovitis, infection, or arthrofibrosis are not uncommon. ${ }^{7}$ DVT and pulmonary embolism (PE) are relatively rare complications following ACL-R but the incidence of asymptomatic DVT is reported to be closed to $15 \%{ }^{8}$ Other studies described a 90-day PE rate of $0.08 \%$ and 90 -day DVT rate of $0.12 \%$ in 301,701 elective arthroscopic procedures. ${ }^{9}$ received

January 15, 2018

accepted after revision

October 7, 2018

published online

November 30, 2018
DOI https://doi.org/

10.1055/s-0038-1675799.

ISSN 2282-4324.
Copyright $\odot 2018$ Georg Thieme Verlag License terms

KG Stuttgart - New York
(®) $\Theta \circledast$ 
Knee joint infection is a rare but potentially devastating complication after ACL-R, with an incidence ranging from 0.14 to $1.70 \%{ }^{10-12}$ Graft choice may be associated to the risk of infection with a reported increased risk for hamstring compared with bone-patellar tendon-bone (BPTB) autograft and for allograft compared with autograft. ${ }^{13-16}$

During graft harvesting, different possible complications may occur, such as patellar fracture, with an incidence ranging between 0.2 and $2.3 \%$ during BPTB graft harvesting. ${ }^{17}$ Similarly, hamstring graft harvesting may be related to different complications, such as the risk to cut the tendons at an undesirably short length. This complication typically occurs when fascial bands are not sufficiently freed off the tendons, forcing the stripper to prematurely amputate the tissue. ${ }^{18}$ Another common complication after ACL-R is postoperative hemarthrosis but it can be avoided using a postoperative drain for 24 hours. McCormack et al found that the hemarthrosis score was statistically smaller 1 week after surgery in the drained group ( $p=0.02$ ) compared with the notdrained one but this difference was no more relevant after 4 or 8 weeks. ${ }^{19}$

Despite the amount of literature regarding common complications following ACL-R, there are few case reports describing uncommon complications. These complications may be divided into six categories: (1) complications related to the fixation devices (rupture or migration); (2) fractures (on tibial or femoral side); (3) infection due to uncommon bacteria and mycosis; (4) rare vascular injuries; (5) nerve injuries; and (6) others complications. The aim of this literature review is to describe diagnosis and treatment of these uncommon complications following ACL-R.

\section{Complications Related to the Fixation Devices}

The fixation devices used in ACL-R can be divided (based on the type of fixation) into suspension, transfixion or expansion, and compression.

Within the compression devices, metallic or absorbable interference screws are the most commonly used for both soft tissue and BPTB grafts. Theoretical advantages of absorbable compared with metallic screws are lower risk of graft injury during fixation, less difficulties during revision surgeries and low interference during magnetic resonance imaging (MRI). Different disadvantages are also described, such as synovitis related to screw absorption, osteolysis around the screw, chronic effusion, and aseptic exudates. ${ }^{20}$ However, a recent Cochrane review did not demonstrate any differences in self-reported outcomes, postoperative activity level, implant breakage during surgery and major postoperative complications between metallic or absorbable interference screws. $^{21}$

Different complications have been described using both absorbable and metallic interference screws for graft fixation. Screw breakage during insertion has been described to be more frequent using absorbable compared with metallic screws, with a rate closed to $10 \%$. Different authors concluded about no association between screw breakage and worse clinical outcome but it may be associated to low primary stability. ${ }^{22}$ Late screw breakage after ACL-R is a rare complication. There are four case reports in literature describing five cases of late absorbable interference screw breakage on the tibial side. ${ }^{23-26}$ In all the cases, the breakage occurred within 1 year after surgery. All patients had minor trauma, such as standing up from a chair, or no trauma. Patients experienced persistent swelling and mechanical symptoms, such as locking or popping. In all the cases an MRI was performed, confirming an intra-articular loose body. All the patients underwent arthroscopic screw removal and in all the cases the screw was located in the intercondylar notch. In one case, the broken screw caused a cartilage damage on the patellar side. In all the cases the symptoms resolved after screw removal and patients completely recovered. ${ }^{23-26}$ Loosening and intra-articular migration of interference screws after ACL-R are also a rare but possible complication, requiring screw removal because of mechanical problems and cartilage damages. Screw migration may be related to a tunnel-screw size mismatch, screw divergence, poor bone quality, tunnel enlargement, or bone resorption due to thermal necrosis during tunnel drilling. ${ }^{27,28}$ Bone tunnels enlargement may be associated to graft-tunnel interface micromotion, accelerated rehabilitation, improper graft fixation or placement, presence of allograft, graft swelling and the so-called "pressureeffect" ${ }^{29}$.There are four papers in literature describing five cases of tibial interference screw migration. ${ }^{28,30-32}$ In three cases the migration occurred within 1 year from the ACL$\mathrm{R},{ }^{30,31}$ while in the last two cases it occurred 1 and 2 years after the surgery. ${ }^{28,32}$ Hamstring graft was used in four cases, ${ }^{30-32}$ while ВРТВ graft was used in the remaining one. $^{28}$ In four cases an intra-articular migration occurred, ${ }^{28,30,31}$ and in the last one the screw migrated extra-articularly and it was palpable under the skin of the proximal tibia. ${ }^{32}$ Screw migration may have different clinical presentations, such as mechanical symptoms, ${ }^{28,31}$ erythema, palpable mass, wound dehiscence, ${ }^{32}$ effusion, and limited range of motion (ROM) ${ }^{30}$ MRI was performed in all the cases to diagnose screw migration. ${ }^{28,30-32}$ Patients underwent arthroscopic device removal and in one case a posteromedial portal was required to remove the screw. ${ }^{28}$ In most of the patients, symptoms disappeared after device removal but one patient complained about a residual instability and a limited ROM. ${ }^{30}$

Transfixion devices, such as cross-pins, may also be used for ACL graft fixation. Some authors preferred absorbable device instead of metallic ones, because of their potential, such as graft irritation, problems during revision procedures, as well as MRI distortion. ${ }^{33}$ Three case reports reporting cross-pin breakage were described in literature. ${ }^{34-36}$ The same fixation device was used in all the cases (RigidFix, Mitek) and a late breakage occurred with patients complaining about sudden effusion, pain, and catching sensation. ${ }^{34-36}$ In two cases an MRI was performed but it was not determinant to assess device breakage. ${ }^{34,35}$ All the cases underwent a diagnostic arthroscopy. In one case the broken device was found in the lateral compartment with associated lateral 
chondral damage. ${ }^{35}$ In the second case, the device was found in the posterolateral corner, lodged in the popliteal hiatus, ${ }^{34}$ while in the last case the device was found in the medial compartment with associated chondral damage. ${ }^{36}$ In all the cases, there were no graft damages and the patients completely recovered after device removal. ${ }^{34-36}$

There are three case reports in literature describing a cortical button migration. In the first case, the button was found in the popliteal space 25 months after surgery and it was arthroscopically removed. ${ }^{37}$ In the second case, the cortical button was found in the knee joint at the 2 years follow-up X-ray. The patient was completely asymptomatic and refused arthroscopic device removal. ${ }^{38}$ In the last case, the patient sustained ACL rerupture 3 years after the primary reconstruction and the X-rays showed intra-articular displacement of the cortical button. The patient underwent an ACL-R revision with button removal. Intraoperatively, it was noted that the femoral tunnel exit was too anterior in the suprapatellar pouch, with suture loop failure and consequent intra-articular displacement of the cortical button. ${ }^{39}$ - Table 1 summarizes these cases.

\section{Rare Fractures}

Patellar fracture may occur during BРTB autograft harvesting. Studies have reported the incidence of intraoperative and postoperative patella fractures with BPTB graft ranging between 0.2 and $2.3 \%{ }^{40}$ Tibial and femoral fractures are less common compared with patellar fractures.

\section{Tibial Fracture}

Tibial fracture is a rare complication following ACL-R. Different factors may be related to increased risk for tibial fracture after ACL-R. Biomechanical studies found that bone defects, for example, due to bony tunnel for an ACL-R may decrease bone strength to torsional loading. Moreover, drill holes may cause a reduction of $20 \%$ of the mineral bone density, reducing the bone strength from 55 to $90 \% .{ }^{41}$ Other authors described a possible association between tunnel enlargement and risk of fracture development. ${ }^{29,42}$ Furthermore, other authors reported an increased risk of tibial fracture if a BPTB graft was used, probably due to the increased stress related to both presence of a tibial defect (for graft harvesting) and the tibial tunnel. ${ }^{43}$ There are 17 case reports in literature describing tibial fracture after ACL-R. ${ }^{43-58}$ However, five case reports were excluded from this review because the fracture was due to a high energy trauma (traffic accident). ${ }^{51-55}$ Furthermore, one case report was excluded because it was written in German language ${ }^{56}$ and one other because it was poorly described. ${ }^{57}$ Moen et al described a proximal tibial fracture at the graft harvesting site due to stress concentration at this location. The patients underwent conservative treatment in a long leg cast and completely recovered from the complication. ${ }^{50}$ In the remaining nine reports, the BPTB graft was used in five cases, ${ }^{43,45-47}$ while soft tissue graft was used in four cases. ${ }^{10,48,49,58}$ In most of the cases the fracture occurred within 6 months from the ACL-R. ${ }^{44,58}$ However, in one case it occurred 4.5 years after surgery due to a minor trauma in a
40 years old man. ${ }^{10}$ Fractures occurred at the tibial tunnel in three cases ${ }^{10,48,49}$ and at the harvesting site in four cases. ${ }^{44-46,58}$ In one case, the fracture begun from the transosseous tunnel and involved the entire tibial plateau. ${ }^{43}$ In the remaining case, the fracture occurred at the graft fixation site at the tibial side. ${ }^{47}$ All patients presented complaining about swelling, hemarthrosis, and inability to bear weight. In seven cases, the fracture was diagnosed with an X-ray ${ }^{43-46,48,58}$ and in seven cases, a computed tomography (CT) scan was obtained to better evaluate fracture morphology $43-45,47,48,58$. In one case the undisplaced tibial plateau fracture was not detected with X-rays and an MRI was necessary to confirm the diagnosis. ${ }^{49}$ Three cases were surgically managed with open reduction and internal fixation, ${ }^{10,45,46}$ one case was surgically treated with a minimally invasive surgical technique using screws. ${ }^{43}$ In all these cases the fracture was displaced. The remaining five cases with an undisplaced fracture were treated with no weight-bearing and cast or brace for 4 to 6 weeks ${ }^{44,47-49}$. In seven cases, patients completely recovered from the complication ${ }^{10,44-47,58}$ but in the remaining two cases, patients complained about postoperative mild decreased ROM. ${ }^{43,49}$ - Table 2 summarized all the case reports previously described.

\section{Femoral Fracture}

Femoral fracture following ACL-R is a rare but devastating complication and it was mostly due to technical errors or to the creation of additional bone holes for supplemental fixation devices. Different authors described a decreased bone mineral density up to $20 \%$ following knee ligament injury that may be involved in the development of femoral fractures during or after ACL-R. ${ }^{59}$ In most of the case reports of femoral fracture after ACL-R, an extra-articular fixation with a $6.5 \mathrm{~mm}$ screw, ${ }^{60}$ staple, $^{61}$ cross-pin, ${ }^{62-65}$ or additional removal of a $6.5 \mathrm{~mm}$ transverse cancellous screw ${ }^{66}$ were related to this complication. Other authors reported multiple cortical passes with the guide pin ${ }^{67,68}$ or drilling for screw placement ${ }^{60}$ as possible risk factor associated for fracture development. Furthermore, tunnel malpositioning with posterior wall blow-out, ${ }^{69}$ vertical tunnel placement, ${ }^{68-70}$ tunnel widening, ${ }^{71}$ and the presence of multiple femoral tunnels in revision ACL- $\mathrm{R}^{72}$ are other possible factors related to femoral fractures. Some authors suggested an increased risk for fracture with femoral tunnel greater than $10 \mathrm{~mm}$ of diameter. ${ }^{61}$ Han et al in their biomechanical study evaluated the possible role of the femoral tunnel as potential stress riser associated with fractures, comparing the risk for fracture between single bundle (SB) and double bundle (DB) techniques. The authors concluded that an anatomic independently drilled single bundle femoral tunnel, whether a BPTB or hamstring graft is used, is not a stress riser for femoral fracture. In their experimental model, there was a significant difference in load to failure in the DB group compared with the SB group. Furthermore, the fracture patterns of the DB group always occurred through both femoral tunnels at the notch, whereas the SB groups had similar fracture patterns throughout the lateral cortex and not always involving the femoral tunnel. ${ }^{59}$ Although the 


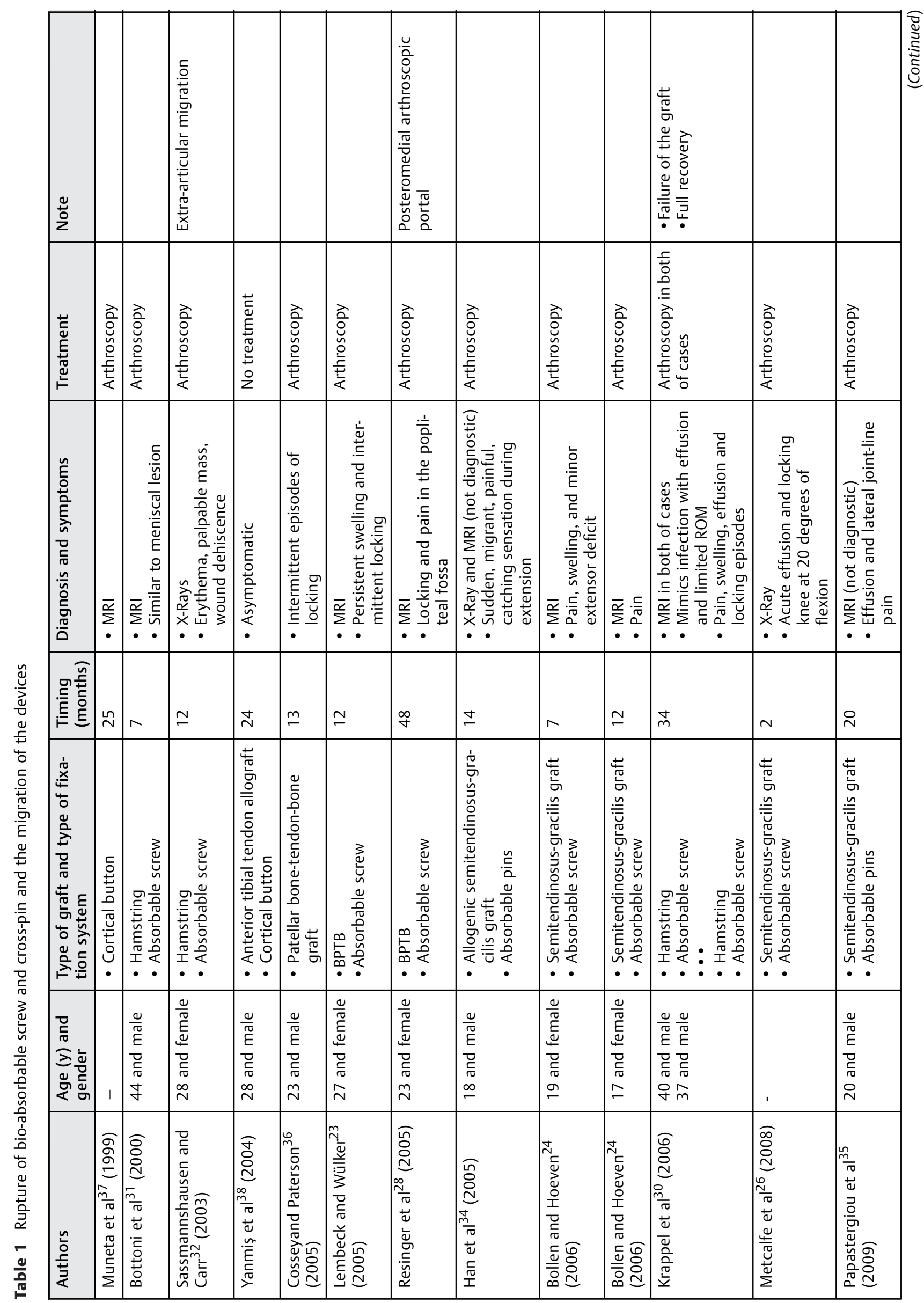




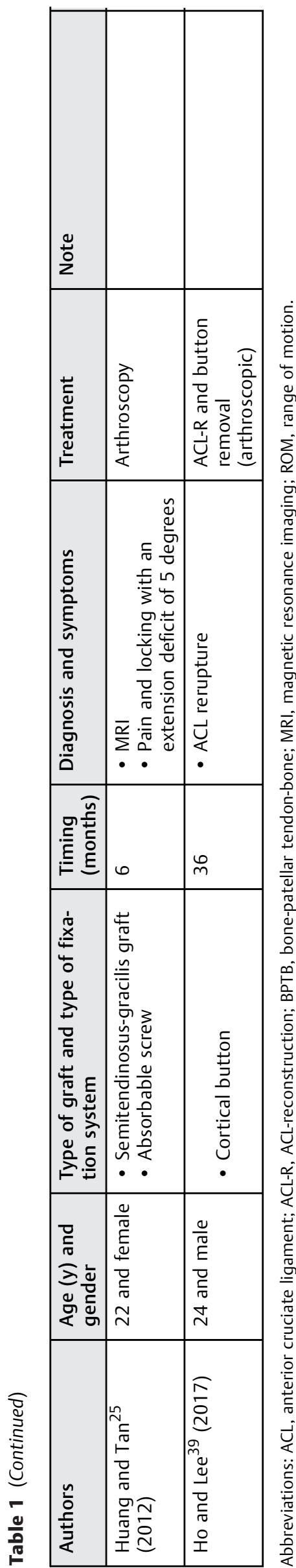

incidence of femoral fracture due to ACL-R is unknown, it is suspected to be extremely low. ${ }^{73}$ There were 13 case reports of femoral fractures after ACL-R in literature including 14 patients. Four papers were excluded because of additional surgical procedure (i.e., lateral tenodesis or multiple ligament reconstruction), ${ }^{42,60}$ high energy trauma related to the fracture $^{53}$ or because complete data for analysis were not available. $^{63}$ In the remaining studies, the fractures occurred in a period ranging from 2 months to 7 years, with one intraoperative fracture. ${ }^{74}$ The case described by Dowen et al deserves an aside discussion. The fracture occurred 7 years after ACL-R on a tumor mass located in the femoral tunnel. The pathological fracture was related to a lytic lesion causing a femoral tunnel enlargement. The mass biopsy confirmed the diagnosis of bone giant cell tumor. The treatment included wide mass debridement, screw removal, and defect filling with polymethyl methacrylate bone cement. Open reduction and internal fixation was then performed to stabilize the fracture. ${ }^{75}$ Different grafts were used in the other case reports: gore-tex graft was used in one case, ${ }^{70}$ BPTB graft was chosen in four cases, ${ }^{29,68,69,71}$ and hamstring graft was used in the remaining cases. ${ }^{61,62,64,66,67,75,76}$ In most of the cases the fracture was due to a low energy trauma, such as knee twisting ${ }^{64,70,71,76}$ and light fall. ${ }^{29,61,69}$ In four cases a stress fracture was described. ${ }^{62,66,68}$ In the last report, the fracture was due to an over-reaming of a previous tunnel in a revision ACL-R. The stress of the reamer to enlarge the previous tunnel caused a coronal fracture in the lateral condyle. The treatment was planned in two stages: first the fracture was treated, then once it was healed, the ACL-R revision was performed. ${ }^{74}$ Clinical presentation was similar in all the cases, with pain and impossible weight-bearing on the affected knee. In all the cases X-Rays and CT scans were performed. Two cases were treated conservatively with complete recovery. ${ }^{62}$ Surgical treatment was performed in the remaining cases, with different strategies for fixation, depending on the fracture morphology. Internal fixation with intramedullary nail was performed in three cases with one good outcome, ${ }^{71}$ one case of postoperative ROM reduction ${ }^{68}$ and one case of mild instability. ${ }^{66}$ Four cases were treated with screws with complete recovery ${ }^{29,61,64}$. In one case there was a fracture displacement 3 months after screws fixation. A second surgical procedure was performed and the fracture was treated using bone grafting and refixation. Despite this second surgery, the presence of a persistent nonunion required a third surgical procedure and the fracture was fixed with a plate. The fracture eventually healed, the knee was stable but the patient complained about a loss of ROM. ${ }^{69}$ In the remaining cases open reduction and internal fixation with plate and screws was performed with good outcomes. $^{67,70,74,76}$-Table 3 summarized the case reports previously described.

\section{Uncommon Infections}

Septic arthritis after ACL-R is a relatively rare but serious complication, associated to high rate of reoperations, need for prolonged antibiotic therapy, graft removal, and delayed 

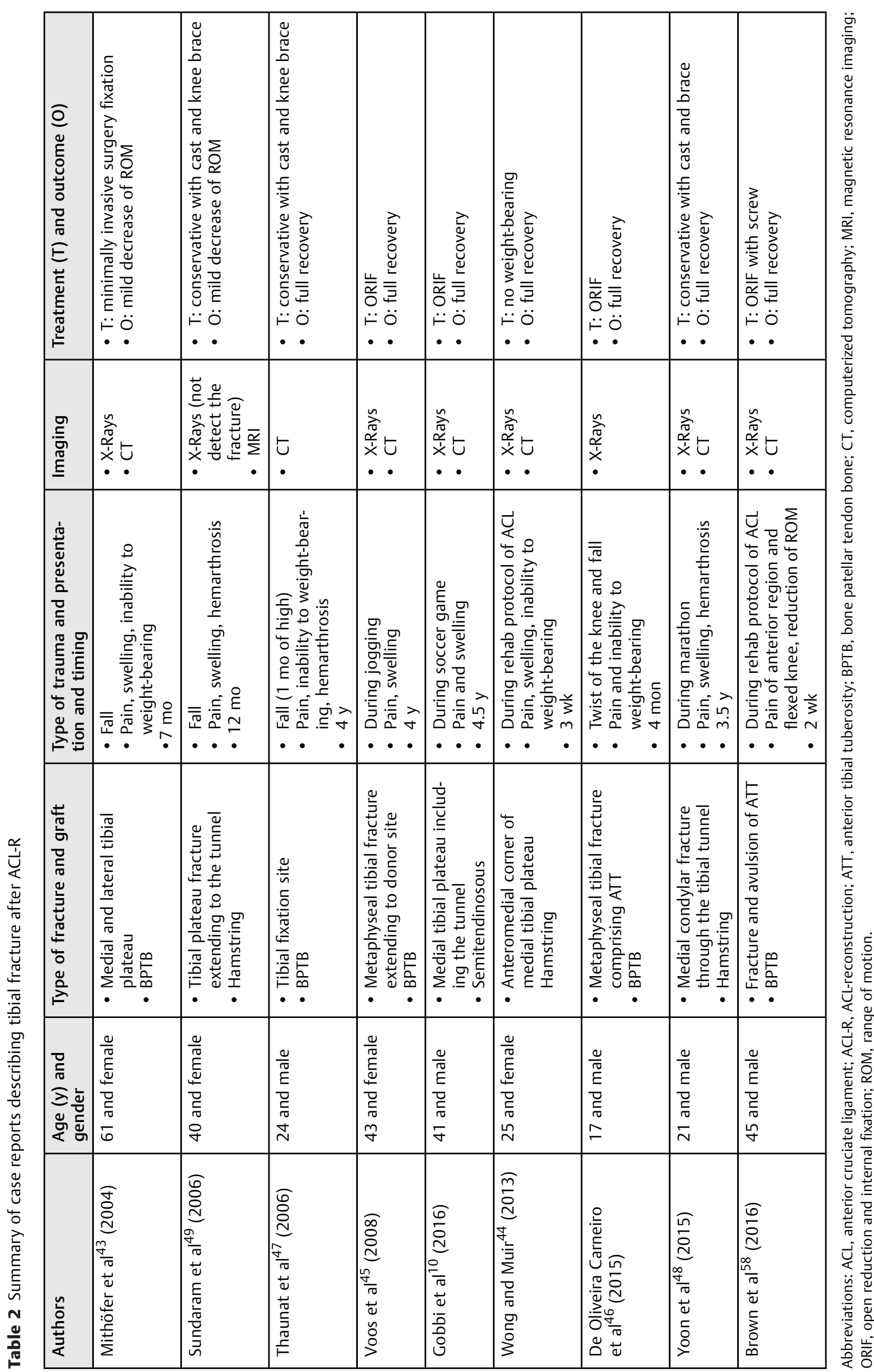


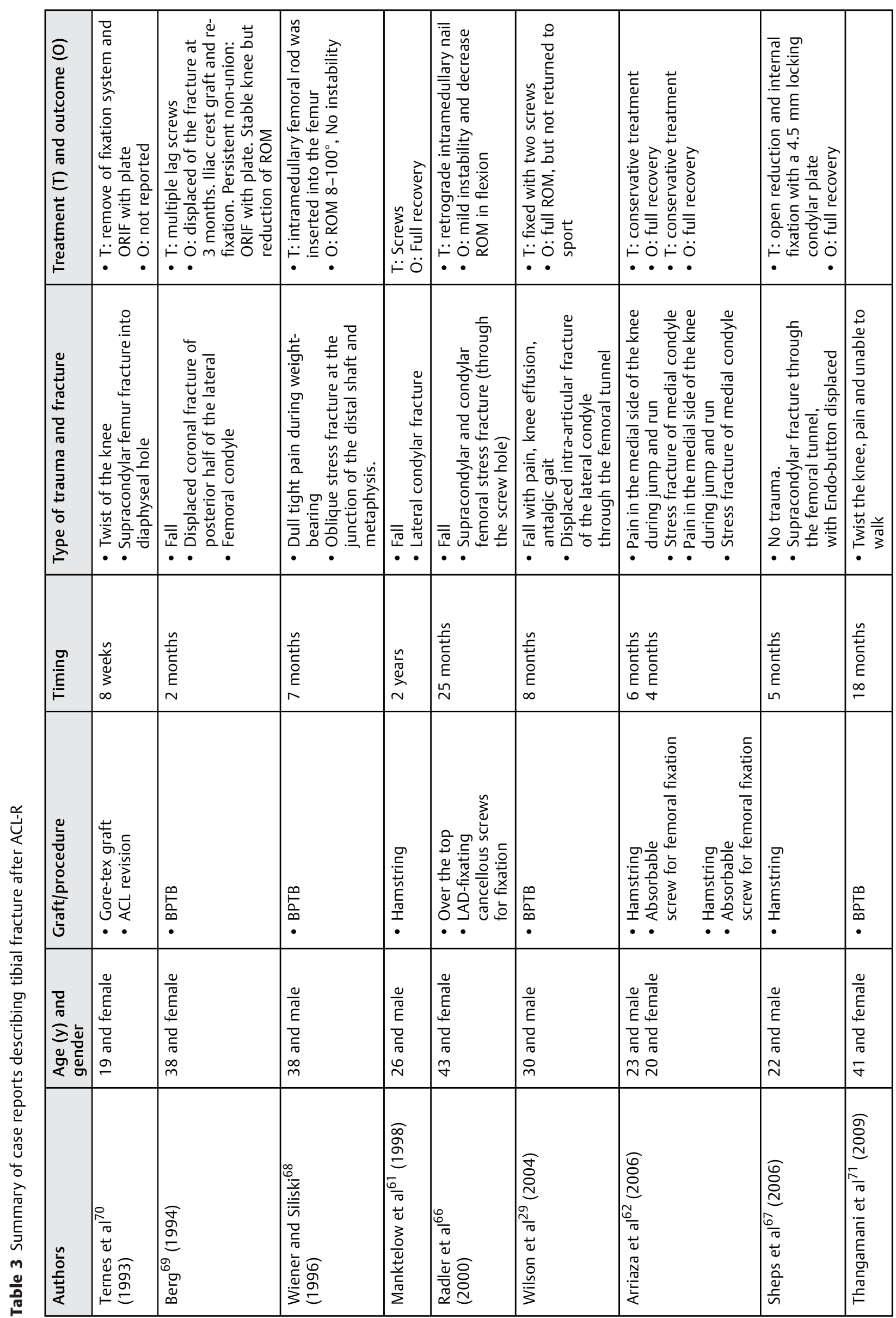




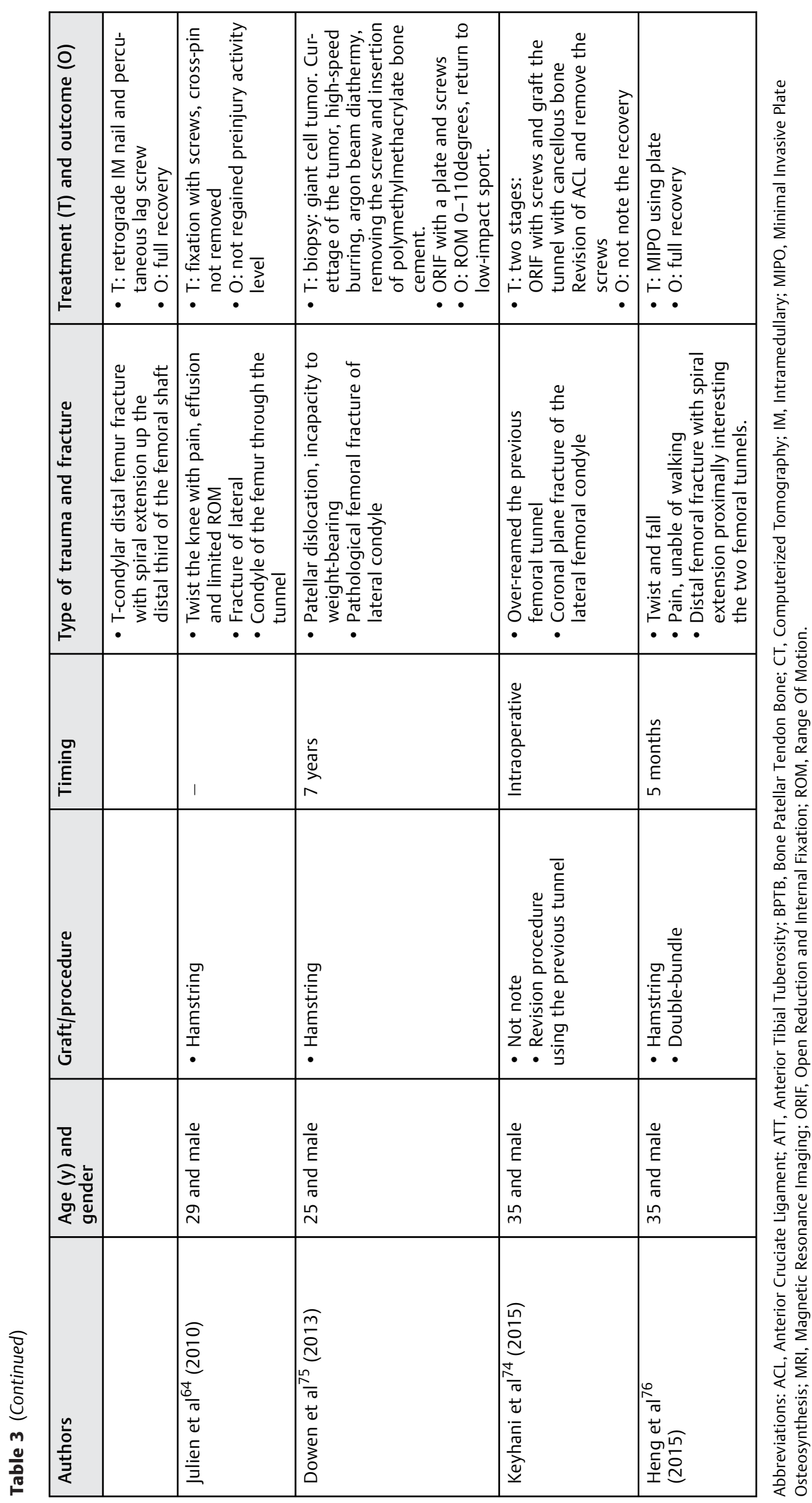


ACL- $R$ revision. The rate of infection after ACL- $R$ reported in the literature ranges between 0.4 and $1.7 \%{ }^{11,14,15,77,78}$ Many different microorganisms were isolated from synovial fluid of septic arthritis, such as Staphylococcus aureus, coagulasenegative Staphylococcus, Propionibacter acnes, Enterobacter, Enterococcus, Pseudomonas aeruginosa, Escherichia coli, Klebsiella and Methicillin-resistant Staphylococcus aureus (MRSA). ${ }^{77}$

Despite these bacteria are the most commonly involved in septic arthritis after ACL-R, there are few case reports describing uncommon pathogens related to ACL-R infection. Mei-Dan et al described an infection caused by Staphylococcus lugdunensis 4 days after an ACL-R performed with a BPTB graft, ${ }^{79}$ while of O'Neill reported a case of osteomyelitis due to a Staphylococcus capitis 4 years after an ACL-R performed with hamstring autograft. ${ }^{80}$ Both pathogens were isolated from synovial fluid culture and the blood tests were suggestive for infection. The patient affected by $S$. capitis infection was treated with antibiotic therapy alone, ${ }^{80}$ while the other patient underwent also an arthroscopic lavage. ${ }^{79}$ Good outcomes with infection eradication were obtained in both the cases $^{79,80}$.

Tubercular joint infection after ACL-R is considered a rare complication in Europe and the U.S.A. However, in an Indian hospital, Nag et al found that $0.69 \%$ ( 8 cases out of 26 septic arthritis) of infections after ACL-R were related to Mycobacterium tuberculosis (MTB). ${ }^{81}$ Diagnostic criteria for septic arthritis due to MTB are: (1) positive stain for acid-fast bacilli (AFB) on joint samples, (2) a positive culture on LöwensteinJensen medium, (3) epithelioid granuloma with or without central caseation and Langhans-type giant cells at the histologic analysis, and (4) positive polymerase chain reaction (PCR) for MPT64 gene of MTB. ${ }^{82}$ Hamstring autograft was used in 7 patients and BPTB autograft in the last one. Four patients had a subacute onset, whereas other four had a late onset. All the patients complained about swelling, whereas warmth was present in 3 cases, low-grade fever in two and pain in the remaining two cases. ${ }^{81}$ Furthermore, an isolated case of MTB infection was described by Oh et al in a 15 yearsold girl who underwent ACL-R with autologous hamstring. She developed a wound dehiscence with yellow exudates and ROM reduction, 3 months after surgery. ${ }^{83}$ In all these cases, blood tests and joint aspiration were performed. Increased erythrocyte sedimentation rate (ESR) and C-reactive protein (CRP) were found in the eight cases from Nag et al, ${ }^{81}$ while normal blood tests resulted in the case described by $\mathrm{Oh}$ et al. ${ }^{83}$ However, in all the cases white blood cell (WBC) count was normal. In the cases described by Nag et al, joint fluid aspiration was turbid with an elevated WBC count but did not show any organism with Gram's stain. All patients underwent arthroscopic debridement and lavage: partial synovectomy was performed and tissue samples were collected and sent for cultures, including specific MTB tests. Cultures were positive for MTB in three patients. Histopathology showed the presence of typical epithelioid tissue in seven cases. AFB was seen in two biopsy specimens. DNA-PCR was performed in six cases and in all the cases it was positive for MTB. All the patients were treated for MTB with good out- comes and complete recovery. ${ }^{81}$ In the case described by $\mathrm{Oh}$ et al, the patient underwent three arthroscopic irrigation and debridement without any success. During the last arthroscopy the fixation screw was removed and sent for both pyogenic and MTB organism cultures. The test showed a massive growth of Mycobacterium fortuitum. Patient begun immediately appropriate pharmacological treatment with complete recovery. ${ }^{83}$

Fungal infection after ACL-R is a rare but devastating complication with severe bone loss mostly due to delayed diagnosis. three case reports of fungal infection after ACL-R are described in literature. Mirzatolooei reported seven patients in which the fungal infection was probably related to a mistake during equipment sterilization and three cases were ACL-R infected by Alternaria. ${ }^{84}$ Muscolo et al described six cases with mycotic infection after primary ACL-R, five cases were positive for Rhizopus microsporus and one case for Candida albicans. ${ }^{85}$ Furthermore, Sun et al described a single case of Aspergillus infection after ACL-R. ${ }^{86}$ In all these cases the symptoms begun 2 to 3 weeks after ACL-R and the clinical presentation were similar with fever, pain, and swelling. In all the cases blood tests as well as joint aspiration were performed. WBCs, ESR, and CRP were increased, the synovial fluid was turbid as in presence of an acute septic arthritis with increased WBCs count and polymorphonuclear neutrophils percentage. All the cultures were negative for bacterial. Systemic antibiotic was promptly begun in all the cases suspecting a low virulence bacterial infection. Serial X-rays and MRI showed cartilage destruction and destructive arthritis in all the cases. ${ }^{84-86}$ Most of the patients did not respond to the antibiotic treatment. In the first patient, Mirzatolooei performed an arthroscopic irrigation and debridement, followed by an open approach to perform wide debridement and fixation device removal. The device was sent for cultures, including fungi, and it resulted positive for Alternaria; antifungal therapy was begun immediately, with infection eradication but ROM reduction. The second and the third patients had the same clinical presentation of the first one, with a faster diagnosis and treatment, resulting in better outcomes. ${ }^{84}$ All the cases described by Muscolo et al underwent a surgical treatment, with a medial para-patellar approach, wide synovectomy, graft and implant removal, curettage, and massive bone resection due to severe bone necrosis involving the distal femur or the proximal tibia med. In some patient, a temporary cement spacer was used to maintain the joint space. In one patient an arthrodesis with intercalary allograft and intramedullary nail was required because of the massive bone losses and extensor apparatus damage. ${ }^{85}$ In the cases described by Sun et al, an empirical antibiotic treatment was initially begun because the notfungal specific cultures resulted negative. The patient underwent arthroscopic irrigation and debridement twice, and the last time a total synovectomy, as well as graft and implant removal was performed. Patients' symptoms did not resolve, so the authors performed an open debridement and tissue samples were sent to three different laboratories, with a positive result for Aspergillus. Antifungal therapy had begun immediately with infection eradication. However, due to the 
massive bone disruption, the patients underwent one more surgery, with bone transport and arthrodesis with Ilizarov's. ${ }^{86}$ In conclusion, fungal infections are rare but devastating complications after ACL-R. The massive bone loss due to late diagnosis often required radical treatment in young patient. - Table 4 summarized these case reports in detail.

\section{Rare Vascular Injuries}

Vascular injuries associated with ACL-R are very rare and account for less than $1 \%$ of all the complications. ${ }^{87,88}$ Injuries to the popliteal artery are more common during posterior cruciate ligament (PCL) reconstruction compared with ACL$\mathrm{R} .{ }^{89}$ However, some minor vessels, such as the geniculate arteries, can also be injured during an ACL-R. There are three case reports in literature describing uncommon vessels injuries during ACL-R. Tsubosaka et al described a case of a pseudo-aneurysm of the articular branch of the descending genicular artery after a double-bundle ACL-R in an 18-yearold male. Two days after surgery, the patient presented with a pulsing mass on the medial side of the knee. Popliteal and dorsal artery pulses were normal. Due to the unusual presentation of the pulsatile mass, CT angiography was performed and showed a pseudo-aneurysm of the articular branch of the descending genicular artery. The pseudoaneurysm was embolized and the patient completely recovered. ${ }^{90}$ Lamo-Espinosa et al reported the case of a 27-yearold male who underwent a single-bundle ACL-R with a BPTB allograft. The day after surgery, the patient presented an active pulsatile bleeding and knee swelling. Arthrocentesis showed haemarthrosis and $60 \mathrm{cc}$ of blood were extracted. Because of the bleeding, patient was referred to endovascular treatment, including an arteriography via the left common femoral artery. After contrast injection, the injury of the inferior lateral genicular (ILG) artery was localized and selectively embolized. ${ }^{91}$ The authors attributed the ILG artery damage to the anterior horn partial meniscectomy of the lateral meniscus because it required passing the shaver close to the synovial capsule and to the ILG. ${ }^{91}$

Kim et al described case of a 31-year-old male who underwent arthroscopic anatomic single-bundle ACL-R. On the day 1 after surgery, the patient complained about pain around his left ankle without motor or sensory deficits. The pulses were palpable in the lower leg. Authors prescribed nonsteroidal anti-inflammatory drugs in the suspicion of an inflammatory process. The day after, the patient complained a small sensory deficit on the dorsal aspect of the foot, without any vascular deficit or pain increase at rest or during passive muscular stretching. After 2 days, the patient presented with a severe edema and pain exacerbation in the ipsilateral lower leg. An angiography was performed showing a thrombosis of both the left popliteal and anterior tibial arteries. The screw tip seemed to be close to the occlusion site in both the arteries. Postoperative X-rays showed that the position of the tibial tunnel was good but the screw was too long and its direction was too posterior. The diagnosis was a compartment syndrome due to direct drilling injury to the anterior tibial artery and a fasciotomy was immediately performed for decompression. The pain was resolved but a debridement and excision of the necrotic extensor hallucis longus, extensor digitorum longus, and anterior tibialis muscles was required 9 days after ACL-R. ${ }^{92}$

\section{Nerve Injuries}

During ACL-R, iatrogenic injuries to the infrapatellar braches of the saphenous nerve are not uncommon, ${ }^{93}$ and some authors described a reduction in their incidence if an oblique skin incision instead a vertical incision is performed for hamstring graft harvesting. ${ }^{94}$ Injuries to the saphenous nerve, ${ }^{95,96}$ the sciatic nerve, ${ }^{97}$ and the common peroneal nerve are less common in ACL-R surgeries. ${ }^{98,99}$ Five case reports are described in literature reporting about rare nerve injuries in ACL-R. ${ }^{95-99}$ One case report was excluded from the analysis because full data were not available. ${ }^{95}$ In one case, a BРTB graft was used, ${ }^{99}$ while in the other patients hamstring autografts were chosen. ${ }^{96-98}$ In all the cases, the symptoms begun immediately with sensory deficit in the medial side of the leg in case of saphenous nerve damage, ${ }^{96}$ in the lateral side of calf muscles and dorsal foot in association to loss of function if the common peroneal nerve was involved $^{98,99}$ or complete sensory and motor deficit of the leg if the sciatic nerve was involved. ${ }^{97}$ In case of saphenous nerve damage, the diagnosis was done with the clinical evaluation. ${ }^{96}$ When a neuropathy of the common peroneal or sciatic nerve was suspected, an MRI and electromyography were performed to evaluate the level and entity of the injury. ${ }^{97,98}$ In the case described by Papoutsidakis et al of peroneal nerve damage, the injury was due to a too long tibial screw that was directed toward the fibular neck; this is the only case in which iatrogenic cause of the injury was described. The screw was removed and the patient recovered. ${ }^{99}$ In the cases described by Vardi ${ }^{97}$ and Balkey and Biant, the injury was probably related to the direction of the tendon stripper during hamstring harvesting. ${ }^{97,98}$ Nerve revision was performed in three cases. In two cases, the damaged nerve was explored and debrided, one patient was fully recovered ${ }^{97}$ and the other one complained about persisting sensory deficit. ${ }^{96}$ In one case, peroneal nerve damage was repaired using a sural nerve graft but the patient still complained about loss of strength, loss of activity, and sensory deficit. ${ }^{98}$

\section{Other Rare Complications}

Myositis ossificans (MO) is as a rare complication after knee surgeries. It is a benign process characterized by heterotopic ossification usually related to muscular trauma, such as contusion or strain. ${ }^{100} \mathrm{MO}$ etiology is still unclear and different theories have been proposed: transformation of intramuscular hematoma into bone, hematoma calcification, intramuscular bone formation from a detached periosteal flap, osteoblast proliferation from periosteal rupture, and metaplasia of intramuscular connective tissue cells. ${ }^{101}$ Yamagami et al described a case of 27-year-old woman who underwent arthroscopic anatomical double-bundle 


\begin{tabular}{|c|c|c|c|c|}
\hline 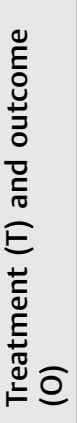 & 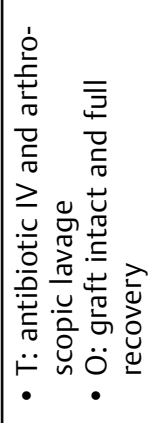 & 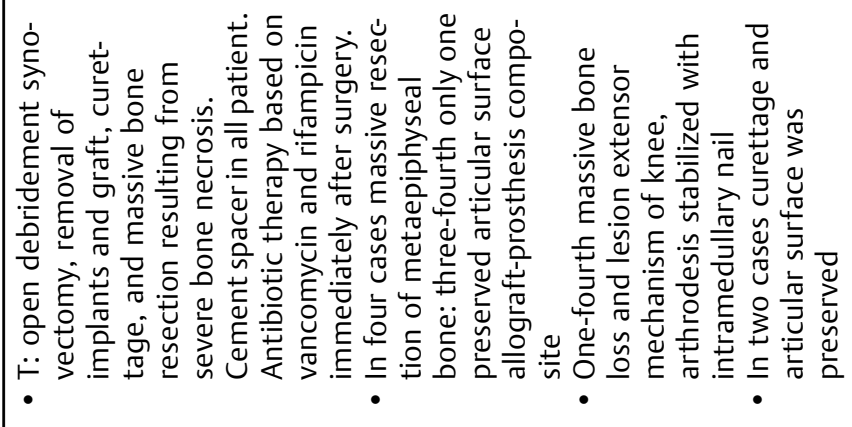 & 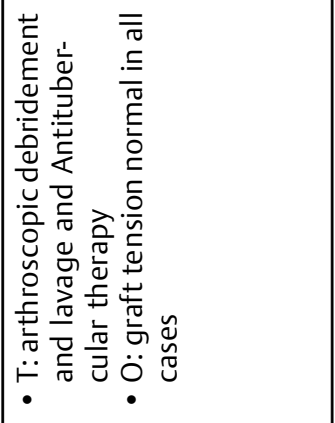 & 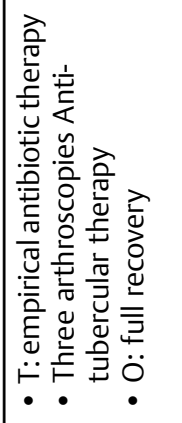 \\
\hline 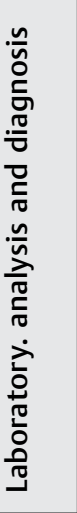 & 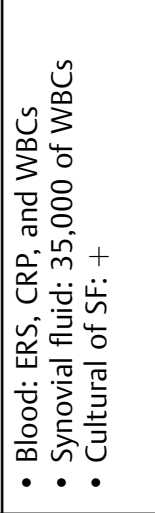 & 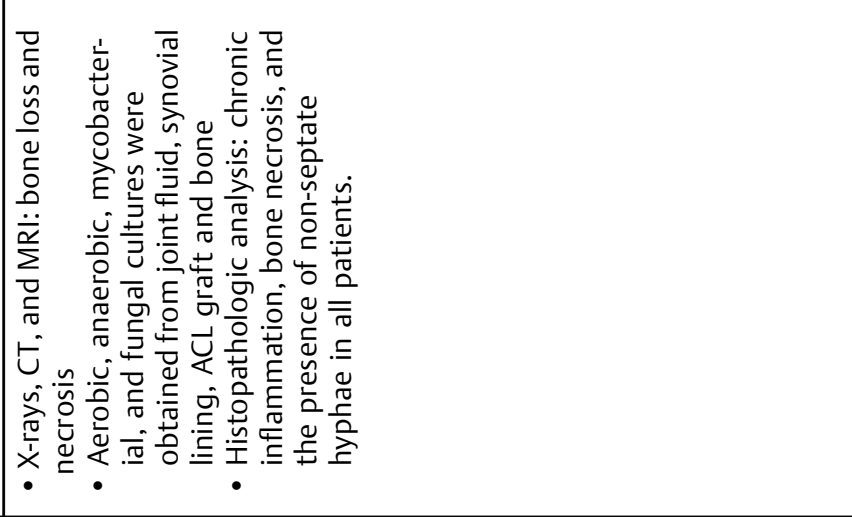 & 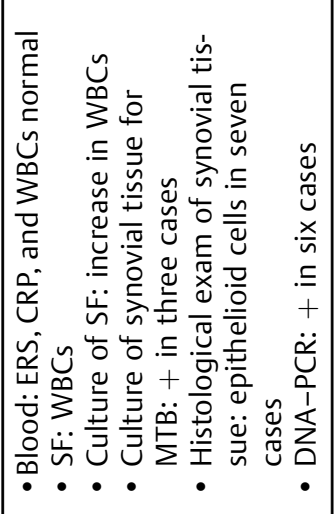 & 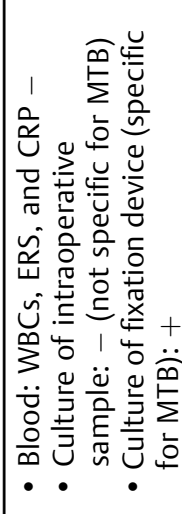 \\
\hline 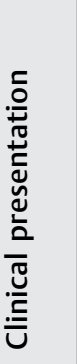 & 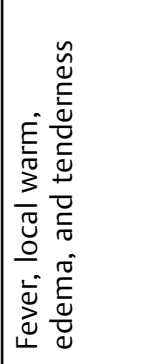 & 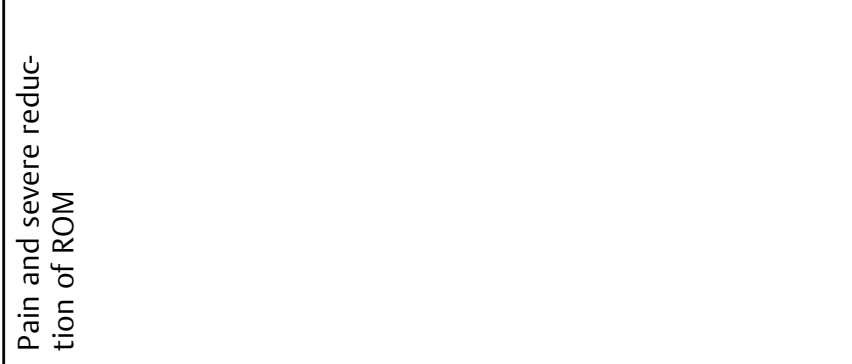 & 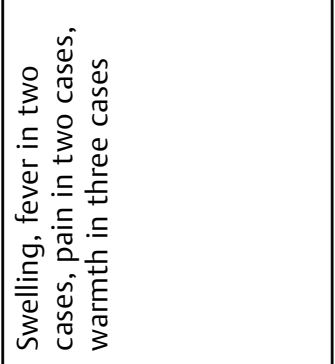 & 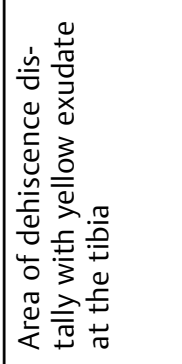 \\
\hline 莺 & 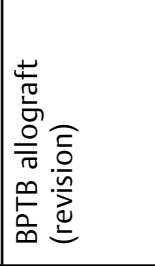 & 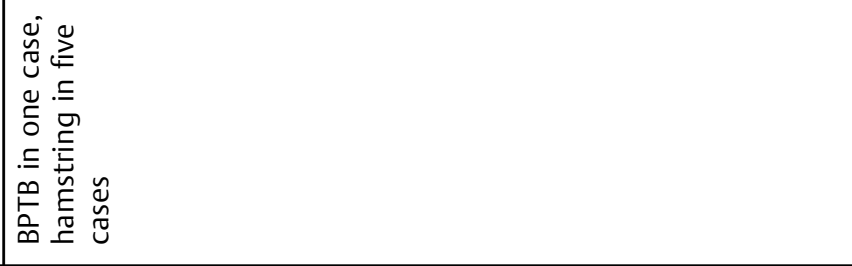 & 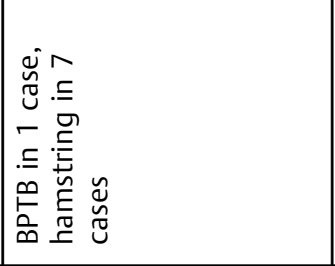 & 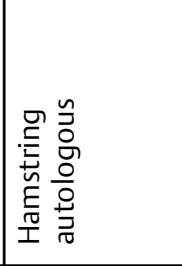 \\
\hline 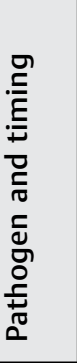 & 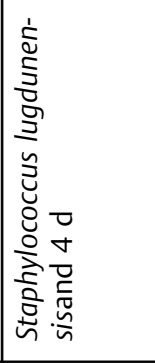 & 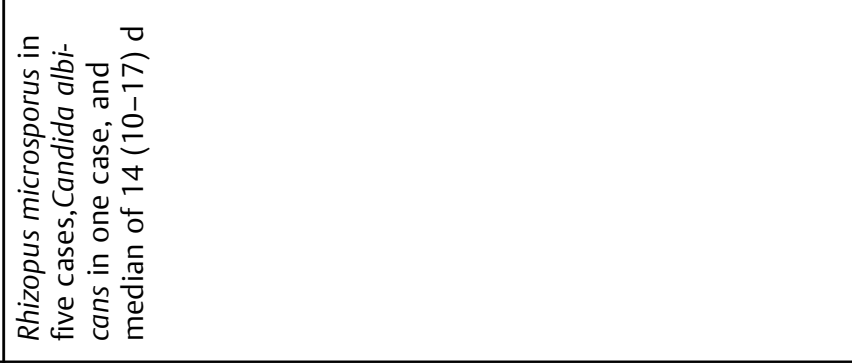 & 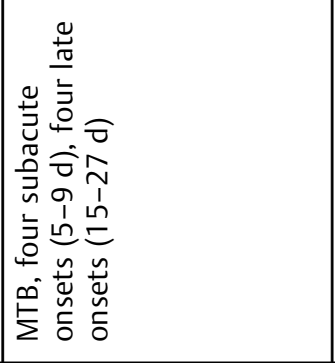 & 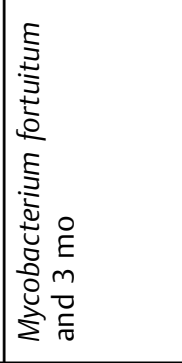 \\
\hline 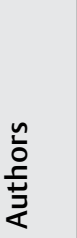 & 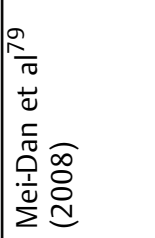 & 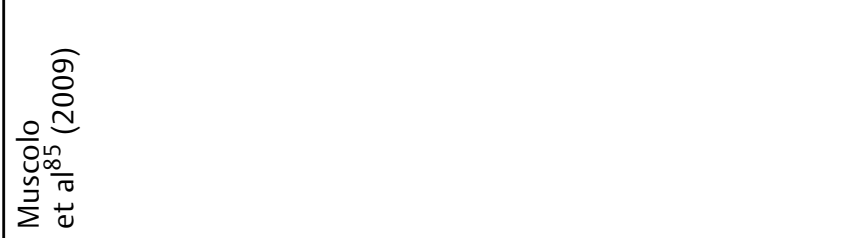 & 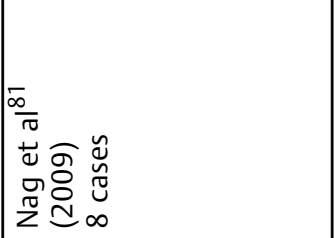 & 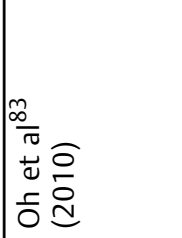 \\
\hline
\end{tabular}



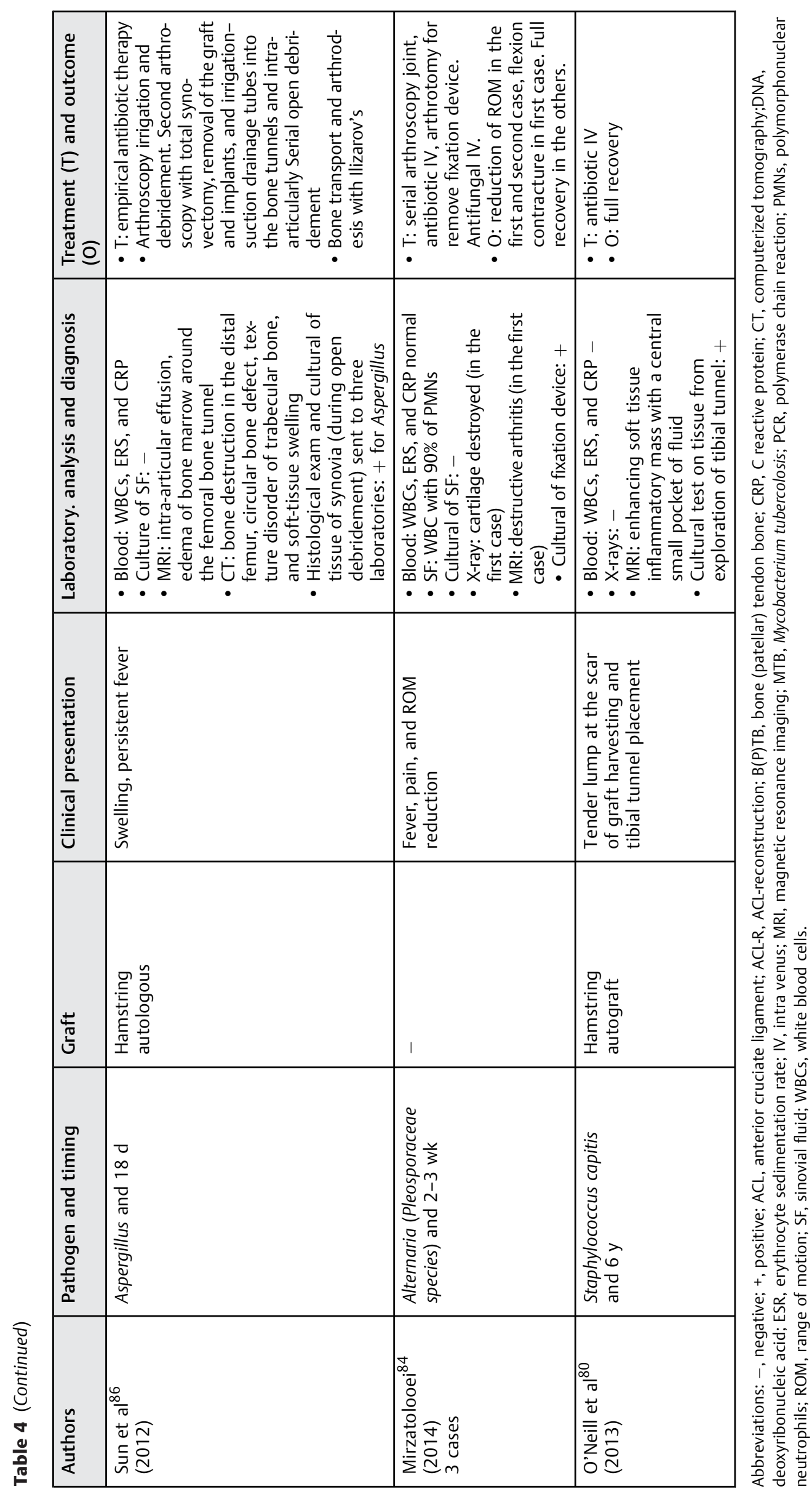
ACL-R with hamstring using a three-dimensional (3D) fluoroscopy-based navigation system (StealthStation TRIA plus; Medtronic, Louisville, CO, U.S.A.) to create the femoral tunnel. Seven weeks after surgery the patient complained about the presence of a solid mass at the distal femur. X-rays and CT scans showed a heterotopic ossification localized at the drill hole performed for reference frame placement. An MRI showed a fluid effusion around the mass. Patient was substantially asymptomatic for pain and loss of function; the rehabilitation program was continued and the patient returned to daily activities without complications. ${ }^{102}$

Another rare complication after ACL-R is pigmented villonodular synovitis (PVNS) development. Rajani et al described the case of a 42-year-old woman with a previous ACL-R (16 years before), who began complaining pain and swelling in the same knee. The clinical examination revealed positive Lachman and anterior drawer test, with a palpable effusion. X-rays showed a radiolucent lesion suggestive for an aggressive process and MRI revealed diffuse PVNS extending along the ACL graft and causing bone loss within the tunnels. An arthroscopic biopsy of the synovium confirmed the diagnosis. The patient underwent a complete synovectomy, and the tibial and femoral bone defects were treated with cancellous bone chips. ${ }^{103}$

\section{Discussion}

ACL-R is a very common orthopedic procedure ${ }^{1}$ with good outcomes but a complication rate ranging from 1 to $15 \%{ }^{6}$ Some relatively common complications are DVT, stiffness, complication related to graft harvesting, and common bacterial infection. However, there are different case reports in literature describing uncommon complications after ACL-R, such as rupture or migration of fixation device, tibial o femoral fractures, uncommon infections (unusual bacterial, mycobacterium, or fungal infection), rare vascular or nerve injuries, and other rare complications (MO and PVNS).

Despite fixation device, such as interference screws and cross-pins are commonly used in ACL-R, surgeons should know that a rupture or migration of the screw is possible, even months after the ACL-R. In these cases, patients may complain about pain, mechanical symptoms, or effusion. Tibial and femoral fractures are rarer compared with patellar fracture in ACL-R. However, they may occur for low energy trauma also months after the ACL-R due to the bone weakness related to the tunnel and a surgical treatment may be required. Different rare infections after ACL-R are described in literature with uncommon clinical presentation and difficult diagnosis. Fungal infections are often misdiagnosed because the patient is young and healthy but late diagnosis can cause dramatic joint disruption. Major vessels injuries are rare after ACL-R but different authors described injuries to minor vessels, such as geniculate arteries, presenting with pulsating masses and treated with selective embolism. Damages to the infrapatellar branch of the saphenous nerve are not uncommon after ACL-R. However, some authors also described few cases with saphenous, common peroneal or sciatic nerve injury associated to ACL-R with potential severe consequences for the patients. Some authors also reported some cases of MO and PVNS after ACL-R.

In conclusion, ACL-R is a pretty common procedure, but surgeons should be aware about common but also rare complications and how to avoid, diagnose, and treat them.

\section{Conflict of Interest}

R.R. is a teaching consultant for Zimmer Biomet and Smith and Nephew. All the other authors report no conflict of interest.

\section{References}

1 Kaeding CC, Léger-St-Jean B, Magnussen RA. epidemiology and diagnosis of anterior cruciate ligament injuries. Clin Sports Med 2017;36(01):1-8

2 Baer GS, Harner CD. Clinical outcomes of allograft versus autograft in anterior cruciate ligament reconstruction. Clin Sports Med 2007;26(04):661-681

3 McCullough KA, Phelps KD, Spindler KP, et al; MOON Group. Return to high school- and college-level football after anterior cruciate ligament reconstruction: a Multicenter Orthopaedic Outcomes Network (MOON) cohort study. Am J Sports Med 2012;40(11):2523-2529

4 Tay KS, Tan AHC. Clinical Outcomes, Return to Sports, and Patient Satisfaction After Anterior Cruciate Ligament Reconstruction in Young and Middle-Aged Patients in an Asian Population-A 2Year Follow-up Study. Arthroscopy 2018;34(04):1054-1059

5 Samitier G, Marcano AI, Alentorn-Geli E, Cugat R, Farmer KW, Moser MW. Failure of Anterior Cruciate Ligament Reconstruction. Arch Bone Jt Surg 2015;3(04):220-240

6 Cinque ME, Chahla J, Moatshe G, et al. Outcomes and complication rates after primary anterior cruciate ligament reconstruction are similar in younger and older patients. Orthop J Sports Med 2017;5(10):2325967117729659

7 Nadarajah V, Roach R, Ganta A, Alaia MJ, Shah MR. Primary anterior cruciate ligament reconstruction: perioperative considerations and complications. Phys Sportsmed 2017;45(02): 165-177

8 Gaskill T, Pullen M, Bryant B, Sicignano N, Evans AM, DeMaio M. The prevalence of symptomatic deep venous thrombosis and pulmonary embolism after anterior cruciate ligament reconstruction. Am J Sports Med 2015;43(11):2714-2719

9 Jameson SS, Dowen D, James P, Serrano-Pedraza I, Reed MR, Deehan DJ. The burden of arthroscopy of the knee: a contemporary analysis of data from the English NHS. J Bone Joint Surg Br 2011;93(10):1327-1333

10 Gobbi A, Karnatzikos G, Chaurasia S, Abhishek M, Bulgherhoni E, Lane J. Postoperative infection after anterior cruciate ligament reconstruction. Sports Health 2016;8(02):187-189

11 Katz LM, Battaglia TC, Patino P, Reichmann W, Hunter DJ, Richmond JC. A retrospective comparison of the incidence of bacterial infection following anterior cruciate ligament reconstruction with autograft versus allograft. Arthroscopy 2008;24 (12):1330-1335

12 Van Tongel A, Stuyck J, Bellemans J, Vandenneucker H. Septic arthritis after arthroscopic anterior cruciate ligament reconstruction: a retrospective analysis of incidence, management and outcome. Am J Sports Med 2007;35(07):1059-1063

13 Bansal A, Lamplot JD, VandenBerg J, Brophy RH. Meta-analysis of the risk of infections after anterior cruciate ligament reconstruction by graft type. Am J Sports Med 2018;46(06):1500-1508

14 Barker JU, Drakos MC, Maak TG, Warren RF, Williams RJ III, Allen AA. Effect of graft selection on the incidence of postoperative 
infection in anterior cruciate ligament reconstruction. Am J Sports Med 2010;38(02):281-286

15 Judd D, Bottoni C, Kim D, Burke M, Hooker S. Infections following arthroscopic anterior cruciate ligament reconstruction. Arthroscopy 2006;22(04):375-384

16 Yu A, Prentice HA, Burfeind WE, Funahashi T, Maletis GB. Risk of infection after allograft anterior cruciate ligament reconstruction: are nonprocessed allografts more likely to get infected? A cohort study of over 10,000 allografts. Am J Sports Med 2018;46 (04):846-851

17 Busam ML, Provencher MT, Bach BR Jr. Complications of anterior cruciate ligament reconstruction with bone-patellar tendonbone constructs: care and prevention. Am J Sports Med 2008; 36(02):379-394

18 Burrus MT, Werner BC, Crow AJ, et al. Increased failure rates after anterior cruciate ligament reconstruction with soft-tissue autograft-allograft hybrid grafts. Arthroscopy 2015;31(12): 2342-2351

19 McCormack RG, Greenhow RJ, Fogagnolo F, Shrier I. Intra-articular drain versus no drain after arthroscopic anterior cruciate ligament reconstruction: a randomized, prospective clinical trial. Arthroscopy 2006;22(08):889-893

20 Saccomanni B. Graft fixation alternatives in anterior cruciate ligament reconstruction. Musculoskelet Surg 2011;95(03): 183-191

21 Debieux P, Franciozi CE, Lenza M, et al. Bioabsorbable versus metallic interference screws for graft fixation in anterior cruciate ligament reconstruction. Cochrane Database Syst Rev 2016;7: CD009772

22 McGuire DA, Barber FA, Elrod BF, Paulos LE. Bioabsorbable interference screws for graft fixation in anterior cruciate ligament reconstruction. Arthroscopy 1999;15(05):463-473

23 Lembeck B, Wülker N. Severe cartilage damage by broken poly-Llactic acid (PLLA) interference screw after ACL reconstruction. Knee Surg Sports Traumatol Arthrosc 2005;13(04):283-286

24 Bollen SM, van der Hoeven H. Broken delta interference screw after ACL reconstruction: a report of two cases. Knee Surg Sports Traumatol Arthrosc 2006;14(09):903-906

25 Huang MD, Tan HA. Broken bioabsorbable tibial interference screw after anterior cruciate ligament $(\mathrm{ACL})$ reconstruction using a semitendinosus-gracilis graft: a case report. Malays Orthop J 2012;6(03):42-44

26 Metcalfe AJ, James SH, Fairclough JA. Spontaneous locking of the knee after anterior cruciate ligament reconstruction as a result of a broken tibial fixation device. Arthroscopy 2008;24(10): 1195-1197

27 Martinek V, Seil R, Lattermann C, Watkins SC, Fu FH. The fate of the poly-L-lactic acid interference screw after anterior cruciate ligament reconstruction. Arthroscopy 2001;17(01):73-76

28 Resinger C, Vécsei V, Heinz T, Nau T. The removal of a dislocated femoral interference screw through a posteromedial portal. Arthroscopy 2005;21(11):1398

29 Wilson TC, Kantaras A, Atay A, Johnson DL. Tunnel enlargement after anterior cruciate ligament surgery. Am J Sports Med 2004; 32(02):543-549

30 Krappel FA, Bauer E, Harland U. The migration of a BioScrew as a differential diagnosis of knee pain, locking after ACL reconstruction: a report of two cases. Arch Orthop Trauma Surg 2006;126 (09):615-620

31 Bottoni CR, Deberardino TM, Fester EW, Mitchell D, Penrod BJ. An intra-articular bioabsorbable interference screw mimicking an acute meniscal tear 8 months after an anterior cruciate ligament reconstruction. Arthroscopy 2000;16(04):395-398

32 Sassmannshausen G, Carr CF. Transcutaneous migration of a tibial bioabsorbable interference screw after anterior cruciate ligament reconstruction. Arthroscopy 2003;19(09):E133-E136

33 Frosch S, Rittstieg A, Balcarek P, et al. Bioabsorbable interference screw versus bioabsorbable cross pins: influence of femoral graft fixation on the clinical outcome after ACL reconstruction. Knee Surg Sports Traumatol Arthrosc 2012;20(11):2251-2256

34 Han I, Kim YH, Yoo JH, Seong SC, Kim TK. Broken bioabsorbable femoral cross-pin after anterior cruciate ligament reconstruction with hamstring tendon graft: a case report. Am J Sports Med 2005;33(11):1742-1745

35 Papastergiou SG, Koukoulias NE, Ziogas E, Dimitriadis T, Voulgaropoulos H. Broken bioabsorbable femoral cross-pin as a cause of a chondral lesion after anterior cruciate ligament reconstruction. BMJ Case Rep 2009;2009:bcr09.2008.0883

36 Cossey AJ, Paterson RS. Loose intra-articular body following anterior cruciate ligament reconstruction. Arthroscopy 2005; 21(03):348-350

37 Muneta T, Yagishita K, Kurihara Y, Sekiya I. Intra-articular detachment of the Endobutton more than 18 months after anterior cruciate ligament reconstruction. Arthroscopy 1999; 15(07):775-778

38 Yanmiş I, Tunay S, Oğuz E, Yildiz C, Ozkan H, Kirdemir V. Dropping of an EndoButton into the knee joint 2 years after anterior cruciate ligament repair using proximal fixation methods. Arthroscopy 2004;20(06):641-643

39 Ho SW, Lee KT. A rare case of intra-articular displacement of EndoButton following anterior cruciate ligament reconstruction. Clin Orthop Surg 2017;9(04):534-536

40 Lee GH, McCulloch P, Cole BJ, Bush-Joseph CA, Bach BR Jr. The incidence of acute patellar tendon harvest complications for anterior cruciate ligament reconstruction. Arthroscopy 2008;24 (02):162-166

41 Burstein AH, Currey J, Frankel VH, Heiple KG, Lunseth P, Vessely JC. Bone strength. The effect of screw holes. J Bone Joint Surg Am 1972;54(06):1143-1156

42 Konan S, Haddad FS. Femoral fracture following knee ligament reconstruction surgery due to an unpredictable complication of bioabsorbable screw fixation: a case report and review of literature. J Orthop Traumatol 2010;11(01):51-55

43 Mithöfer K, Gill TJ, Vrahas MS. Tibial plateau fracture following anterior cruciate ligament reconstruction. Knee Surg Sports Traumatol Arthrosc 2004;12(04):325-328

44 Wong JJ, Muir B. Insufficiency fracture of the tibial plateau after anterior cruciate ligament reconstructive surgery: a case report and review of the literature. J Can Chiropr Assoc 2013;57(02): 123-131

45 Voos JE, Drakos MC, Lorich DG, Fealy S. Proximal tibia fracture after anterior cruciate ligament reconstruction using bonepatellar tendon-bone autograft: a case report. HSS J 2008;4 (01):20-24

46 de Oliveira Carneiro M, de Almeida Monteiro T, Zenovello Bueno MR, Augustin Júnior JL. Fracture of the proximal extremity of the tibia after anterior cruciate ligament reconstruction: case report. Rev Bras Ortop 2015;50(03):356-359

47 Thaunat M, Nourissat G, Gaudin P, Beaufils P. Tibial plateau fracture after anterior cruciate ligament reconstruction: Role of the interference screw resorption in the stress riser effect. Knee 2006;13(03):241-243

48 Yoon JR, Jeong HI, Wang JH, Jang KM, Yang JH. Tibial plateau fracture after single bundle anterior cruciate ligament reconstruction using post-tie washer-screw fixation. J Orthop Sci 2015;20(01):205-208

49 Sundaram RO, Cohen D, Barton-Hanson N. Tibial plateau fracture following gracilis-semitendinosus anterior cruciate ligament reconstruction: the tibial tunnel stress-riser. Knee 2006;13 (03):238-240

50 Moen KY, Boynton MD, Raasch WG. Fracture of the proximal tibia after anterior cruciate ligament reconstruction: a case report. Am J Orthop 1998;27(09):629-630

51 el-Hage ZM, Mohammed A, Griffiths D, Richardson JB. Tibial plateau fracture following allograft anterior cruciate ligament (ACL) reconstruction. Injury 1998;29(01):73-74 
52 Delcogliano A, Chiossi S, Caporaso A, Franzese S, Menghi A. Tibial plateau fracture after arthroscopic anterior cruciate ligament reconstruction. Arthroscopy 2001;17(04):E16

53 Polyzois I, Manidakis N, Graham S, Tsiridis E. An unusual periarticular fracture following ipsilateral anterior cruciate ligament reconstruction. Knee Surg Sports Traumatol Arthrosc 2009;17(05):503-507

54 Bae KC, Cho CH, Lee KJ, Jeon JH. Bilateral medial tibial plateau fracture after arthroscopic anterior cruciate ligament reconstruction. Knee Surg Relat Res 2015;27(02):129-132

55 Anderson AW, Smith JJ. Proximal tibial fracture after patellar tendon autograft for ipsilateral ACL reconstruction. J Knee Surg 2009;22(02):142-144

56 Thietje R, Faschingbauer M, Nürnberg HJ. [Spontaneous fracture of the tibia after replacement of the anterior cruciate ligament with absorbable interference screws. A case report and review of the literature]. Unfallchirurg 2000;103(07):594-596

57 Morgan E, Steensen RN. Traumatic proximal tibial fracture following anterior cruciate ligament reconstruction. Am J Knee Surg 1998;11(03):193-194

58 Brown MJ, Bisson LJ, Anders MJ. Tibial tubercle fracture after bone-patellar tendon-bone autograft. Am J Orthop 2016;45(07): E469-E471

59 Han Y, Sardar Z, McGrail S, Steffen T, Martineau PA. Peri-anterior cruciate ligament reconstruction femur fracture: a biomechanical analysis of the femoral tunnel as a stress riser. Knee Surg Sports Traumatol Arthrosc 2011;19(Suppl (Suppl 1):S77-S85

60 Noah J, Sherman OH, Roberts C. Fracture of the supracondylar femur after anterior cruciate ligament reconstruction using patellar tendon and iliotibial band tenodesis. A case report. Am J Sports Med 1992;20(05):615-618

61 Manktelow AR, Haddad FS, Goddard NJ. Late lateral femoral condyle fracture after anterior cruciate ligament reconstruction. A case report. Am J Sports Med 1998;26(04):587-590

62 Arriaza R, Señaris J, Couceiro G, Aizpurua J. Stress fractures of the femur after ACL reconstruction with transfemoral fixation. Knee Surg Sports Traumatol Arthrosc 2006;14(11):1148-1150

63 Jayadev C, Kochhar T, Back DL, Ratnakumar K. Supracondylar femoral fracture after anterior cruciate ligament reconstruction with transfemoral fixation. J Knee Surg 2009;22(04):364-366

64 Julien TP, Ramappa AJ, Rodriguez EK. Femoral condylar fracture through a femoral tunnel eleven years after anterior cruciate ligament reconstruction: a case report. J Bone Joint Surg Am 2010;92(04):963-967

65 Montgomery CO, Evans RP. Arthroscopic reduction and internal fixation of a medial femoral condylar fracture after anterior cruciate ligament reconstruction. A case report. J Bone Joint Surg Am 2008;90(04):863-868

66 Radler C, Wozasek GE, Seitz H, Vécsei V. Distal femoral fracture through the screw hole of a ligament augmentation device fixation. Arthroscopy 2000;16(07):737-739

67 Sheps DM, Reed JG, Hildebrand KA, Hiemstra LA. Supracondylar femur fracture after endoscopic anterior cruciate reconstruction using an EndoButton. Clin J Sport Med 2006;16(05):428-429

68 Wiener DF, Siliski JM. Distal femoral shaft fracture: a complication of endoscopic anterior cruciate ligament reconstruction. A case report. Am J Sports Med 1996;24(02):244-247

69 Berg EE. Lateral femoral condyle fracture after endoscopic anterior cruciate ligament reconstruction. Arthroscopy 1994;10(06): 693-695

70 Ternes JP, Blasier RB, Alexander AH. Fracture of the femur after anterior cruciate ligament reconstruction with a GORE-TEX prosthetic graft. A case report. Am J Sports Med 1993;21(01): 147-149

71 Thangamani VB, Flanigan DC, Merk BR. Intra-articular distal femur fracture extending from an expanded femoral tunnel in an anterior cruciate ligament $(\mathrm{ACL})$ reconstructed knee: a case report. J Trauma 2009;67(06):E209-E212
72 Coobs BR, Spiridonov SI, LaPrade RF. Intra-articular lateral femoral condyle fracture following an ACL revision reconstruction. Knee Surg Sports Traumatol Arthrosc 2010;18(09): 1290-1293

73 Stein DA, Hunt SA, Rosen JE, Sherman OH. The incidence and outcome of patella fractures after anterior cruciate ligament reconstruction. Arthroscopy 2002;18(06):578-583

74 Keyhani S, Vaziri AS, Shafiei H, Mardani-Kivi M. Femoral condyle fracture during revision of anterior cruciate ligament reconstruction: case report and a review of literature. Arch Bone Jt Surg 2015;3(02):137-140

75 Dowen D, Kakkar R, Dildey P, Gerrand C. Pain and fracture after anterior cruciate ligament reconstruction caused by giant cell tumour of the distal femur. BMJ Case Rep 2013;2013. Doi: 10.1136/bcr-2013-010422

76 Heng $\mathrm{CH}$, Wang BdeH, Chang PC. Distal femoral fracture after double-bundle anterior cruciate ligament reconstruction surgery. Am J Sports Med 2015;43(04):953-956

77 Stucken C, Garras DN, Shaner JL, Cohen SB. Infections in anterior cruciate ligament reconstruction. Sports Health 2013;5(06):553-557

78 Maletis GB, Inacio MC, Reynolds S, Desmond JL, Maletis MM, Funahashi TT. Incidence of postoperative anterior cruciate ligament reconstruction infections: graft choice makes a difference. Am J Sports Med 2013;41(08):1780-1785

79 Mei-Dan O, Mann G, Steinbacher G, Ballester SJ, Cugat RB, Alvarez PD. Septic arthritis with Staphylococcus lugdunensis following arthroscopic ACL revision with BPTB allograft. Knee Surg Sports Traumatol Arthrosc 2008;16(01):15-18

80 O'Neill BJ, Molloy AP, McCarthy T. Osteomyelitis of the tibia following anterior cruciate ligament reconstruction. Int J Surg Case Rep 2013;4(02):143-145

81 Nag HL, Neogi DS, Nataraj AR, Kumar VA, Yadav CS, Singh U. Tubercular infection after arthroscopic anterior cruciate ligament reconstruction. Arthroscopy 2009;25(02):131-136

82 Park DY, Kim JY, Choi KU, et al. Comparison of polymerase chain reaction with histopathologic features for diagnosis of tuberculosis in formalin-fixed, paraffin-embedded histologic specimens. Arch Pathol Lab Med 2003;127(03):326-330

83 Oh HL, Chen DB, Seeto BG, Macdessi SJ. Mycobacterium fortuitum infection after anterior cruciate ligament reconstruction using a polylactic acid bioabsorbable screw: Case report. Knee 2010;17(02):176-178

84 Mirzatolooei F. Outbreak of serial knee joint sepsis after arthroscopic surgery: a case series with the guideline for treatment. Acta Med Iran 2014;52(04):310-314

85 Muscolo DL, Carbo L, Aponte-Tinao LA, Ayerza MA, Makino A. Massive bone loss from fungal infection after anterior cruciate ligament arthroscopic reconstruction. Clin Orthop Relat Res 2009;467(09):2420-2425

86 Sun L, Zhang L, Wang K, Wang W, Tian M. Fungal osteomyelitis after arthroscopic anterior cruciate ligament reconstruction: a case report with review of the literature. Knee 2012;19(05): 728-731

87 Rossi R, Bonasia DE, Blonna D, Assom M, Castoldi F. Prospective follow-up of a simple arthroscopic-assisted technique for lateral tibial plateau fractures: results at 5 years. Knee 2008;15(05): 378-383

88 Sadat U, Naik J, Verma P, et al. Endovascular management of pseudoaneurysms following lower limb orthopedic surgery. Am J Orthop 2008;37(05):E99-E102

89 Zawodny SR, Miller MD. Complications of posterior cruciate ligament surgery. Sports Med Arthrosc Rev 2010;18(04): 269-274

90 Tsubosaka M, Matsushita T, Kuroda R, Matsumoto T, Kurosaka M. Pseudoaneurysm of the articular branch of the descending genicular artery following double-bundle anterior cruciate ligament reconstruction. Knee Surg Sports Traumatol Arthrosc 2017;25(09):2721-2724 
91 Lamo-Espinosa JM, Llombart Blanco R, Valentí JR. Inferior lateral genicular artery injury during anterior cruciate ligament reconstruction surgery. Case Rep Surg 2012;2012:457198

$92 \mathrm{Kim} \mathrm{SB}$, Lim JW, Seo JG, Ha JK. Injury to the anterior tibial artery during bicortical tibial drilling in anterior cruciate ligament reconstruction. Clin Orthop Surg 2016;8(01):110-114

93 Kartus J, Ejerhed L, Eriksson BI, Karlsson J. The localization of the infrapatellar nerves in the anterior knee region with special emphasis on central third patellar tendon harvest: a dissection study on cadaver and amputated specimens. Arthroscopy 1999; 15(06):577-586

94 Papastergiou SG, Voulgaropoulos H, Mikalef P, Ziogas E, Pappis G, Giannakopoulos I. Injuries to the infrapatellar branch(es) of the saphenous nerve in anterior cruciate ligament reconstruction with four-strand hamstring tendon autograft: vertical versus horizontal incision for harvest. Knee Surg Sports Traumatol Arthrosc 2006;14(08):789-793

95 Nelissen E, van Arkel ER, Hazelbag HM. Traumatic neuroma of the infrapatellar branch of the saphenous nerve after hamstring harvesting. J Knee Surg 2010;23(04):233-236

96 Bertram C, Porsch M, Hackenbroch MH, Terhaag D. Saphenous neuralgia after arthroscopically assisted anterior cruciate ligament reconstruction with a semitendinosus and gracilis tendon graft. Arthroscopy 2000;16(07):763-766
97 Vardi G. Sciatic nerve injury following hamstring harvest. Knee 2004;11(01):37-39

98 Blakey CM, Biant LC. Transection of the common peroneal nerve during harvesting of tendons for anterior cruciate ligament reconstruction. A case report. J Bone Joint Surg Am 2008;90 (07):1567-1569

99 Papoutsidakis A, Drosos GI, Koukou OI, Piskopakis N, Verettas DA. Peroneal nerve damage by bicortical tibial screw in ACL reconstruction. Knee Surg Sports Traumatol Arthrosc 2010;18(06): 794-796

100 McCarthy EF, Sundaram M. Heterotopic ossification: a review. Skeletal Radiol 2005;34(10):609-619

101 Muir B. Myositis ossificans traumatica of the deltoid ligament in a 34. year old recreational ice hockey player with a 15 year posttrauma follow-up: a case report and review of the literature. J Can Chiropr Assoc 2010;54(04):229-242

102 Yamagami R, Taketomi S, Inui H, Sanada T, Nakagawa T, Tanaka S. Myositis ossificans after navigated knee surgery: a report of two cases and literature review. Knee 2016;23 (03):561-564

103 Rajani R, Ogden L, Matthews CJ, Gibbs CP. Diffuse pigmented villonodular synovitis as a rare cause of graft failure following anterior cruciate ligament reconstruction. Orthopedics 2018;41 (01):e142-e144 